\title{
Endangered Grevy's zebra in the Alledeghi Wildlife Reserve, Ethiopia: species distribution modeling for the determination of optimum habitat
}

\author{
Fanuel Kebede ${ }^{1, *}$, Afework Bekele ${ }^{2}$, Patricia D. Moehlman ${ }^{3}$, Paul H. Evangelista ${ }^{4}$ \\ ${ }^{1}$ Ethiopian Wildlife Conservation Authority, Box 386, Addis Ababa, Ethiopia \\ ${ }^{2}$ Department of Biology, Addis Ababa University, PO Box 1176, Addis Ababa, Ethiopia \\ ${ }^{3}$ IUCN/SSC Equid Specialist Group, Box 2031, Arusha, Tanzania \\ ${ }^{4}$ Natural Resource Ecology Laboratory, Colorado State University, Fort Collins, Colorado 80523-1499, USA
}

\begin{abstract}
Habitat loss due to human-induced factors is intensifying and is a critical threat to most endangered species. Grevy's zebra Equus grevyi is one of the most endangered mammals in the world. Human encroachment on its natural habitat and poaching are the greatest threats to this species' survival in the wild. Grevy's zebra only occur within a few isolated areas in Ethiopia and Kenya. Effective conservation interventions based on scientific information are needed to safeguard this species from extinction. Wildlife managers need to identify the extent of the remaining suitable habitat and achieve a better understanding of human and wildlife interactions if they are to facilitate appropriate conservation strategies. The present study employed the maximum entropy model (Maxent), a species distribution modeling approach, to determine the geographic extent of habitat and seasonal distribution of Grevy's zebra in the Alledeghi Wildlife Reserve, Ethiopia, and to use this information to determine the optimum demarcation of conservation boundaries. Field surveys were conducted 4 times annually, twice during the wet season and twice during the dry season, for 2 yr. Field data and predictor variables were separated into 2 seasons, and models were generated for each season independently. Seasonal maximum temperatures, distance to human settlements and slope were the best predictors for both the dry and wet seasons. Evaluations of model performances were high, with AUC (area under the receiver operating curve) values of 0.96 and 0.97 for the dry and wet seasons, respectively. Our results will be critical for modifying the existing boundaries of the Alledeghi Wildlife Reserve and directing conservation strategies for the Grevy's zebra.
\end{abstract}

KEY WORDS: Endangered species $\cdot$ Ethiopia $\cdot$ Grevy's zebra $\cdot$ Habitat modeling $\cdot$ Maxent model

\section{INTRODUCTION}

There is a critical need for the development of conservation strategies for wild equids based on scientific data and methodologies (Moehlman 2002). Wild equids have a unique genetic heritage and play a significant role in maintaining semi-arid and desert ecosystem processes in Africa and Asia. Populations of wild equids have declined significantly due to habitat loss and unsustainable hunting (Williams 2002, Moehlman et al. 2008, IUCN 2010). Historically, the Grevy's zebra Equus grevyi ranged from east of the Rift Valley in Kenya to western Somalia and northern Ethiopia (Bauer et al. 1994). Today its distribution is discontinuous, and the Grevy's zebra is one of the world's most threatened wild equids and is IUCN red-listed as Endangered (Moehlman et al. 2008). 
Grevy's zebra is extinct in Djibouti and Somalia, and it is uncertain whether the species continues to persist in Sudan (Moehlman et al. 2008). In Kenya, between 1977 and 1988, populations of Grevy's zebra declined from 13718 to 4276 individuals (Dirschl \& Wetmore 1978, KREMU 1989). This dramatic decline was attributed to hunting (Rowen \& Ginsberg 1992), the loss of access to habitat due to the presence of domestic livestock, and to low juvenile survival rates in areas where Grevy's zebra share resources with livestock (Williams 1998). In 2000, Nelson \& Williams (2003) reported a further decline, with a total population estimate of between 2435 and 2707 individuals. By 2006, the population in Kenya was estimated to be between 1468 and 2135 (B. Low pers. comm. 2007). In 2007, population estimates slightly increased to 1838 to 2319 individuals, suggesting that more animals were being accurately observed or that the population might be stabilizing and increasing (Mwasi \& Mwangi 2007). However, even if the numbers of Grevy's zebra are stabilizing in Kenya, the population has seen a significant decline from 1988 to 2006 (between 50 and $60 \%$ ) and remains vulnerable to extinction.

In Ethiopia, populations of Grevy's zebra declined from an estimated 1900 in 1980 to 577 in 1992 (Rowen \& Ginsberg 1992) to 106 in 2003 (Williams et al. 2003). The trend from 1980 to 2003 (23 yr) represented a decline of roughly $94 \%$ (Moehlman et al. 2008). In the early 1970s, the largest population of Grevy's zebra in Ethiopia was in the Chew Bahir Wildlife Reserve, which had an estimated 1500 animals; today <30 remain (F. Kebede pers. obs. 2009). In the Alledeghi Wildlife Reserve the numbers of Grevy's zebra declined from about 300 in 1978 (Stephenson 1978) to a total of 177 observed in a 1995 aerial total count (Thouless 1995). Currently, the Alledeghi population encompasses at least 143 Grevy's zebra (F. Kebede pers. comm. 2011).

Listed as Endangered, the current estimate for the total population of Grevy's zebra remaining in the wild in Kenya and Ethiopia is approximately from 1966 to 2447 (B. Lowe pers. comm. 2008; F. Kebede pers. comm. 2008). From 1988 to 2007, the global population of Grevy's zebra declined by approximately $55 \%$. The worst decline was $68 \%$ of the population from 1980 to 2007. The number of mature individuals is approximately 750, and the largest subpopulation includes approximately 255 mature individuals (Moehlman et al. 2008).

The Alledeghi Wildlife Reserve is the northernmost range of the Grevy's zebra, and the population of Grevy's zebra on this reserve is the largest one in
Ethiopia today. The reserve is also home to a number of other important wildlife species, including Soemmering's gazelle Gazella soemmeringi, Beisa oryx Oryx gazella, gerenuk Litocranius walleri, Salt's dikdik Madoqua saltiana, golden jackal Canis aureus, spotted hyena Crucuta crucuta, aardwolf Proteles cristatus and ostrich Struthio camelus. The area not only provides wildlife habitat but is also important grazing land for the Afar and Issa pastoral communities. The livelihoods of pastoral communities in the Alledeghi region are dependent on livestock; and in common pastoral tradition, livestock numbers are a social indication of the owner's wealth (Kebede 1999, Borgerhoff Mulder et al. 2010). Large numbers of livestock depend on the Alledeghi rangeland, resulting in territorial disputes among local pastoralists and grazing competition between livestock and wildlife. It has also been reported that some individuals from local pastoral communities occasionally hunt Grevy's zebra illegally for medicinal purposes and for food (Kebede et al. 2003, 2006, Kebede \& Moehlman 2008). As a result, habitat loss, competition with livestock for forage and water, and illegal hunting all pose major threats to the survival of Grevy's zebra on the Alledeghi plain. Unfortunately, these are not the only threats to the Alledeghi's wildlife. Urban development along the road and recent water borehole development inside the Alledeghi Wildlife Reserve have exacerbated the problem. Traditionally, pastoralists utilized the rangeland on a seasonal basis; however, new boreholes and access to groundwater in the villages allow the pastoralists and their livestock to occupy the area throughout the year, further restricting wildlife movement. Additionally, Prosopis juliflora, an invasive shrub, has rapidly spread throughout the Alledeghi Wildlife Reserve, especially near villages and cattle trails (Kebede \& Moehlman 2008, Kebede 2009), resulting in loss of forage and overall habitat degradation. Due to recent and developing threats to the Grevy's zebra, wildlife managers need to determine actions and prioritize strategies for the conservation of its habitats and seasonal ranges.

Species distribution models (SDM) have been widely used for many applications in conservationand management-related fields (Cowley et al. 2000, Stockwell \& Peterson 2002, Gibson et al. 2004). SDMs have been used to predict and identify distributions of rare and cryptic wildlife species (Pearson et al. 2007, Evangelista et al. 2008a), assess risks associated with invasive species (Ficetola et al. 2007, Rodder et al. 2009), determine areas prone to human and wildlife conflicts (Braunisch et al. 2011), identify 
habitats (York et al. 2011), and define conservation priorities (Thomaes et al. 2008, Baldwin 2009, Thorn et al. 2009). Generally, SDMs use geo-statistical analyses to establish relationships between species occurrences (e.g. observations, scat and tracks) and environmental variables (e.g. elevation, slope, vegetation type, temperature and precipitation) to define the species' ecological niche (Elith et al. 2006). Maximum entropy (Maxent) modeling is one of several SDMs developed in recent years that have become a valuable tool for predicting species distribution (Phillips et al. 2004, 2006). The Maxent model relates presence-only data (i.e. geographic coordinates of species presence) with selected environmental variables to produce a probability model of a species' distribution based on Hutchinson's (1957) classical niche concept. Several comparative studies on SDMs have shown that Maxent performs better than other similar geospatial models (Hernandez et al. 2006, Evangelista et al. 2008b, Kumar et al. 2009). The main objectives of this research were to use the Maxent model to determine the geographic extent of habitat and seasonal distribution of Grevy's zebra in the Alledeghi Wildlife Reserve and to use this information to determine the optimum demarcation of the boundaries to meet management and conservation goals.

\section{MATERIALS AND METHODS}

\section{Study area}

The Alledeghi Wildlife Reserve is 1 of 8 wildlife reserves in Ethiopia. It is located in the Great Rift Valley in the northern region of the country (approximately $8^{\circ} 30^{\prime}$ to $9^{\circ} 30^{\prime} \mathrm{N}$, $39^{\circ} 30^{\prime}$ to $40^{\circ} 30^{\prime} \mathrm{E}$; Fig. 1 ). Located within the Inter-Tropical Convergence Zone, the area exhibits both temporal and spatial variability in rainfall, humidity and temperature. It is a semiarid ecosystem with annual rainfall ranging between 400 and $700 \mathrm{~mm}$ (Gemechu 1977). The area is known for 2 distinct rainy seasons: the small rains usually begin in February and last until the end of April and the big rains occur from July to September. The mean seasonal temperature ranges from 25 to $30^{\circ} \mathrm{C}$, but the daily maximum temperature may be as high as $38^{\circ} \mathrm{C}$ in June, while the minimum daily temperature can drop to $15^{\circ} \mathrm{C}$ in December (Gemechu 1977). The Alledeghi Wildlife Reserve is a grassland plain with high mountains rising on the eastern border. Most of the plain is dominated by the perennial grasses Chrysopogon plumulosus and Sporoblus iocladus.
The southern, eastern and western edges of the reserve are mixed shrub and grasslands dominated by Acacia senegal (Kebede et al. 2002).

The Alledeghi Wildlife Reserve covers an area of $1832 \mathrm{~km}^{2}$ and was established in the 1960s when most of Ethiopia's Wildlife Protected Areas were designated (Hillman 1993). The principal objective for the establishment of this reserve was to protect the endangered Grevy's zebra Equus grevyi and other important grazing wild herbivores that occurred in the area. At present, the reserve is home to Ethiopia's largest population of Grevy's zebra (Williams 2002, Kebede et al. 2006, Kebede 2008) and serves as a buffer zone for the adjacent Awash National Park and the Awash West Wildlife Reserve (Schloeder \& Jacobs 1993).

\section{Data collection}

Ground wildlife surveys were conducted within the Alledeghi Wildlife Reserve on a quarterly basis from 2009 to 2010, during the dry (May and November)

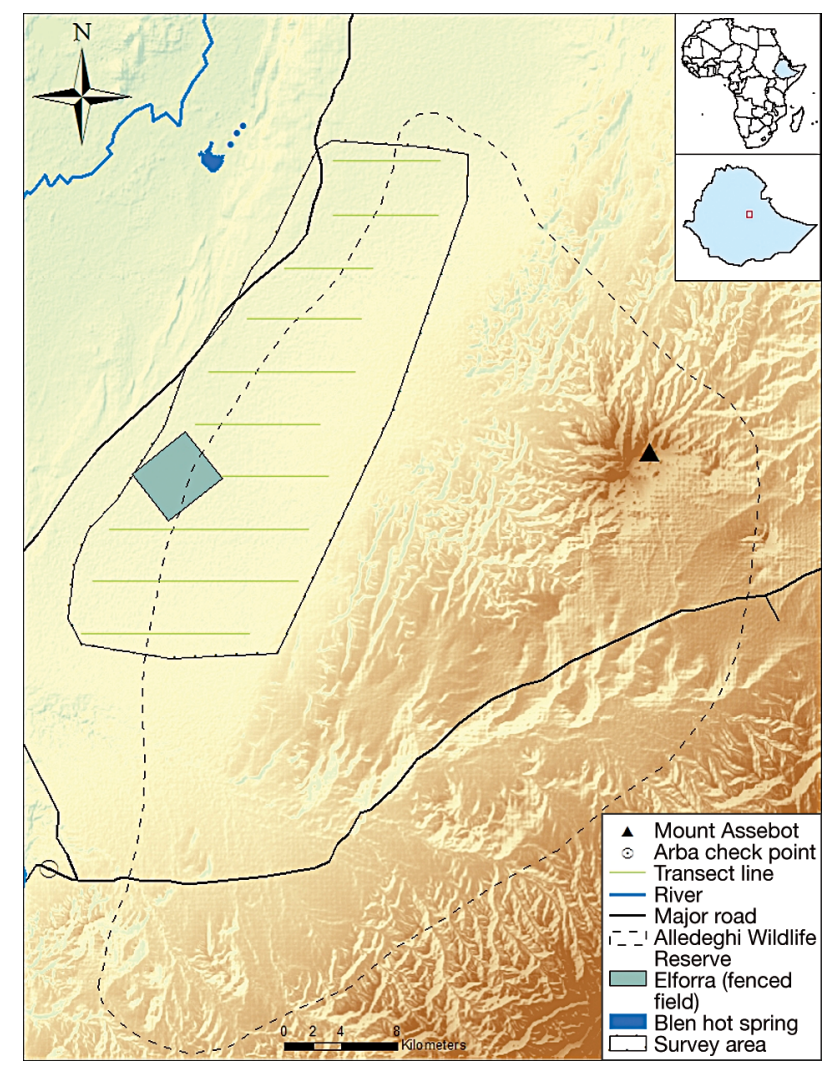

Fig. 1. Alledeghi Wildlife Reserve study area, Ethiopia, with major landscape features and transects lines used for wildlife surveys, 2009 and 2010. Insets depict the location of Ethiopia in Africa and the location of the Alledeghi Wildlife Reserve in Ethiopia 
and wet (March and September) seasons in both years. Each field trip lasted approximately $15 \mathrm{~d}$. Line transect counts (Fig. 1) were used to collect basic information on wildlife and livestock populations that occurred in the Alledeghi grassland plain. A $40 \mathrm{~km}$ base-line was established perpendicular to the parallel transects (Norton-Griffiths 1978). The transect lines were systematically placed $3.66 \mathrm{~km}$ apart with an east-west orientation. This orientation was designed to maximize data collection for conditions on the landscape and minimize the sampling error (Norton-Griffiths 1978). The transect lengths varied from 8 to $15 \mathrm{~km}$, with the shortest transects occurring at the northern end of the study area. The shorter transect lengths were due to security concerns (i.e. tribal conflict between Afar and Issa). In addition to the transect counts, a ground survey was conducted to acquire additional information on water sources, human settlement and habitation, herd sizes of Grevy's zebra, and the collection of fecal samples. The coordinates of fecal droppings were recorded with a Global Positioning System (GPS) and were included in the field data as a presence point for the modeling.

Because the Alledeghi Wildlife Reserve is an open grassland plain, off-road driving along transect lines was the most efficient method for conducting surveys. The driving speed was 10 to $20 \mathrm{~km} \mathrm{~h}^{-1}$ throughout the census period. A spotting scope was used to determine group size, age and sex of Grevy's zebra and other wildlife species. Start and end points of each transect, location points and perpendicular distance to Grevy's zebra were recorded using a GPS in a World Geodetic System, 1984 (WGS 84), and a laser rangefinder was used to determine the perpendicular distance from the point of observation to the individual or groups of animals' locations. The location coordinates of the animal were later determined by adding or subtracting the perpendicular distance to the recorded GPS locations. Counting was conducted within a $1 \mathrm{~km}$ wide strip on each side of the transect. The total area sampled was $218 \mathrm{~km}^{2}$, representing approximately $40 \%$ of the study area $\left(533 \mathrm{~km}^{2}\right)$. Visibility was good throughout the survey area, and Grevy's zebra can be spotted at a sighting distance beyond a kilometer. Transects were driven from 06:00 to $10: 00 \mathrm{~h}$ in the morning and from 16:00 to 18:00 $\mathrm{h}$ in the late afternoon, when wildlife were most active. If $>1$ individual or fecal pile fell within a single pixel representing an area of $90 \mathrm{~m}^{2}$, then the duplicates were removed so that the pixel would represent a single occurrence or presence point. Because of this only (18 observed and 5 fecal) pres- ence points for the wet season and (16 observed and 7 fecal) presence points for the dry season were utilized. This reduced the number of presence points (i.e. observations and fecal piles) to 23 for both the wet and dry seasons $\left(\mathrm{N}_{\mathrm{wet}}=23, \mathrm{~N}_{\mathrm{dry}}=23\right)$.

\section{Predictor variables}

The spatial and temporal distributions of a given species are highly influenced by certain environmental conditions (Barnard \& Thuiller 2008). Fluctuations in the quality and quantity of critical resources, such as water and forage, are particularly important for wildlife species in semi-arid ecosystems. However, settlement and agriculture are among the main driving factors limiting habitat use and distribution of Grevy's zebra in the Alledeghi Wildlife Reserve (Kebede \& Moehlman 2008).

Environmental predictors for the Maxent models were selected to best represent the conditions that are conducive or constraining to Grevy's zebra distribution in the reserve, including abiotic and biotic factors. Eight predictor variables were selected based on available data sets and the researchers' assumptions. These predictor variables included a $90 \mathrm{~m}$ digital elevation model (DEM), derived slope in degrees, monthly minimum/maximum temperature and mean precipitation from the WorldClim database (www. worldclim.org; Hijmans et al. 2005), percent tree cover from the Global Land Cover Facility (www. landcover.org) and user-generated distance from water and settlements. Monthly minimum and maximum temperature and mean precipitation were averaged for 2 mo: the sampling month and its previous month. These months were selected because of their influence on forage production and on the distribution patterns of Grevy's zebra during the sampling period. Tree cover was selected because we expected a negative relationship to Grevy's zebra distribution since individuals have never been recorded in areas with thick Acacia bush during all surveys conducted between 2002 and 2010 (Kebede et al. 2003, 2005, 2006, Kebede 2008). Slope, distance from water sources and distance from settlements were calculated using toolsets available in ArcGIS v. 9.2 (ESRI, www.esri.com). All predictor variables were projected to WGS 84 UTM Zone $37 \mathrm{~N}$ and clipped to the extent of the study area. Climatic variables and tree cover were acquired at a resolution of $1 \mathrm{~km}^{2}$. We re-sampled these variables to $90 \mathrm{~m}$ resolution to match the resolution of our other predictor variables as required to run the Maxent model. 


\section{Spatial analysis}

Maxent is a relatively recent modeling method developed for predicting species distributions and habitat suitability (www.cs.princeton.edu/ schapire/ maxent/; Phillips et al. 2004, 2006). Originally designed as a general-purpose predictive model, Maxent operates on the principle of maximum entropy, making inferences from available data while avoiding unfounded constraints from the unknown (Phillips et al. 2006). Entropy is the measure of uncertainty associated with a random variable. The greater the entropy, the greater the uncertainty. Adhering to these concepts, Maxent utilizes presence-only points of occurrence, avoiding absence data and evading assumptions on the range of a given species.

Evaluations of model performance are automatically generated in Maxent using several methods. First, Maxent calculates the area under the receiver operating curve (AUC). An AUC value of 0.5 indicates a model that predicts no better than chance. Higher values up to a maximum value of 1 indicate much better model performance (see Elith et al. 2006, Peterson et al. 2007). Second, a jackknife option allows the estimation of the bias and standard error in the statistics and can test variable importance. Finally, Maxent can generate response curves for each predictor variable allowing the user to visually see trends within the data (Phillips et al. 2004, 2006). When running the Maxent model for the wet and dry seasons, we ran 25 replicate models randomly withholding $20 \%$ of the presence points $(n=4)$ each time. Then 10000 background points were automatically selected by Maxent from the rectangular block shown in Fig. 2 while performing the analysis. The final map outputs and evaluations were averaged from the 25 replicates for both seasons.

We defined distribution preference, or, in this case, 3 habitat suitability categories (i.e. unsuitable, suitable and optimal) based on 2 threshold values generated by Maxent: (1) minimum training presence logistic threshold and (2) maximum test sensitivity plus specificity logistic threshold. A habitat with values below the minimum threshold was considered as unsuitable, a habitat that fell between minimum and maximum thresholds was considered as suitable, and a habitat with values greater than the maximum threshold was considered optimal. Model results for the wet and dry seasons were overlaid to produce a final map that represented the distribution of Grevy's zebra in the Alledeghi Wildlife Reserve throughout the year.

\section{RESULTS}

The Maxent models for the wet and dry seasons had average AUC values of $0.97 \pm 0.034$ and $0.96 \pm 0.030$, respectively. The minimum training presence logistic threshold and maximum test sensitivity plus specificity logistic threshold values were 0.199 and 0.439 for the wet season, and 0.114 and 0.303 for the dry season, respectively. The distribution maps (Fig. 2) show that Grevy's zebra Equus grevyi have a larger area of optimal habitat during the dry season compared to the wet season. The distribution of Grevy's zebra covered $437 \mathrm{~km}^{2}$ during the wet season and $563 \mathrm{~km}^{2}$ during the dry season. Of these total seasonal ranges, the extent of suitable and optimal habitats was 273 and $164 \mathrm{~km}^{2}$, respectively, for the wet season and 306 and $257 \mathrm{~km}^{2}$, respectively, for the dry season. The annual range for the Grevy's zebra was $669 \mathrm{~km}^{2}$, with $427 \mathrm{~km}^{2}$ as suitable habitat and $242 \mathrm{~km}^{2}$ as optimal habitat.
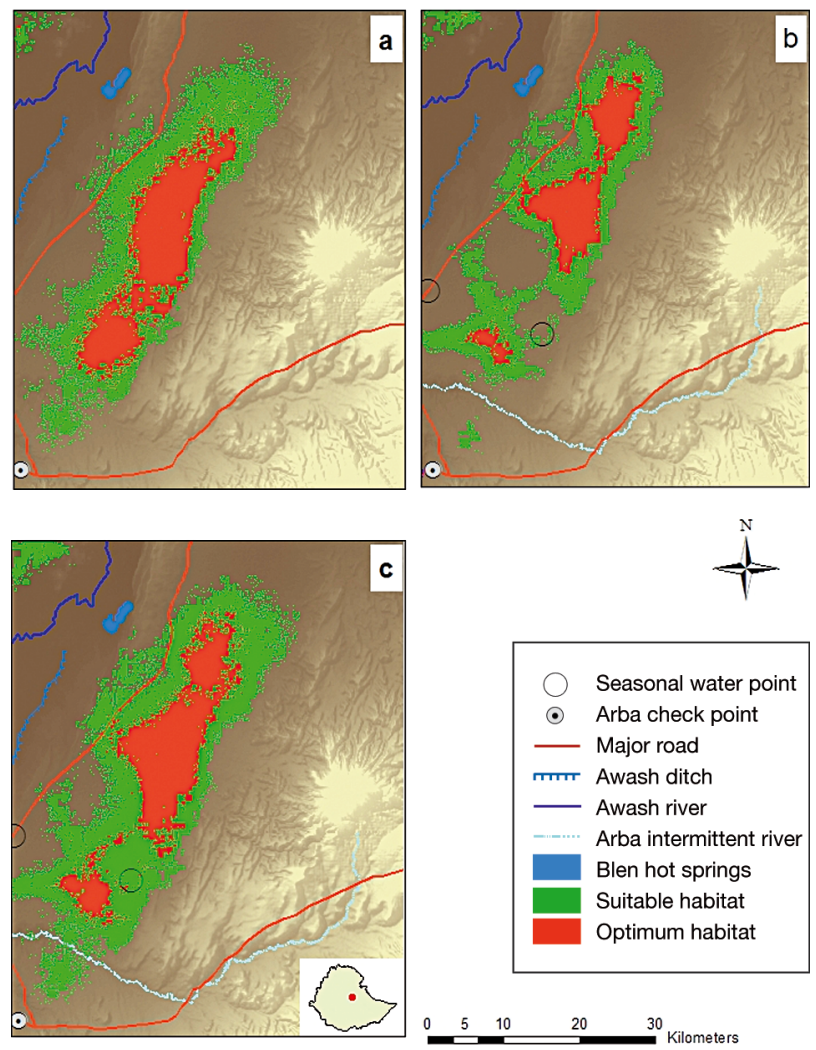

Fig. 2. Estimated habitat for Grevy's zebra in the Alledeghi Wildlife Reserve, Ethiopia, during the (a) dry season, (b) wet season and (c) throughout the year, derived from the Maxent model using wildlife survey data from 2009 and 2010. Inset depicts the location of the Alledeghi Wildlife Reserve in Ethiopia 
Three variables, distance from settlement, slope and maximum temperature, were the most important predictors, having the greatest contribution to the model results for both the wet and dry seasons (Table 1). Jackknife tests (Figs. 3 \& 4) showed the highest AUC gain for precipitation for both wet and dry seasons, indicating that it had the greatest predictive value of all variables when considered independently. In contrast, percent tree cover for both seasons showed the least AUC gain when tested independently.

\section{DISCUSSION}

Based on the evaluations for the Grevy's zebra Equus grevyi, the Maxent models showed a strong performance and should provide wildlife managers with valuable information to guide conservation efforts. Some of the results were expected, while others revealed new insights into the behavior of Grevy's zebra and their response to human activities. The Maxent results showed that all of the predictor variables showed some degree of contribution to the model outputs, each varying with wet and dry seasons. However, 3 predictor variables were consistently strong predictors: distance from settlement/farmland, slope and maximum temperature. The influence that pastoral people and their activities have on Grevy's zebra distributions and concentrations supports previous reports. Our results, coupled with observations from the field (Kebede et al. 2003, 2006, Kebede \& Moehlman 2008, F. Kebede pers. obs.), led us to hypothesize that some of the predictor variables used in the models may have greater influence on the distribution of people

Table 1. Relative contribution of predictor variables to the Maxent model in an analysis of the habitat of Grevy's zebra in both the dry and wet seasons (average results of 25 replicates)

\begin{tabular}{|lcc|}
\hline \multirow{2}{*}{ Predictor variable } & \multicolumn{2}{c|}{ Percent contribution } \\
& Dry season & Wet season \\
\hline Distance from & & \\
settlement/farmland & 26.7 & 21.6 \\
Slope & 26.6 & 24.5 \\
Maximum temperature & 18.7 & 26.4 \\
Precipitation & 12.9 & 5.6 \\
Minimum temperature & 7.4 & 12 \\
Distance from water & 5.1 & 2.9 \\
Tree cover & 1.6 & 1.9 \\
Elevation & 1 & 5.1 \\
\hline
\end{tabular}

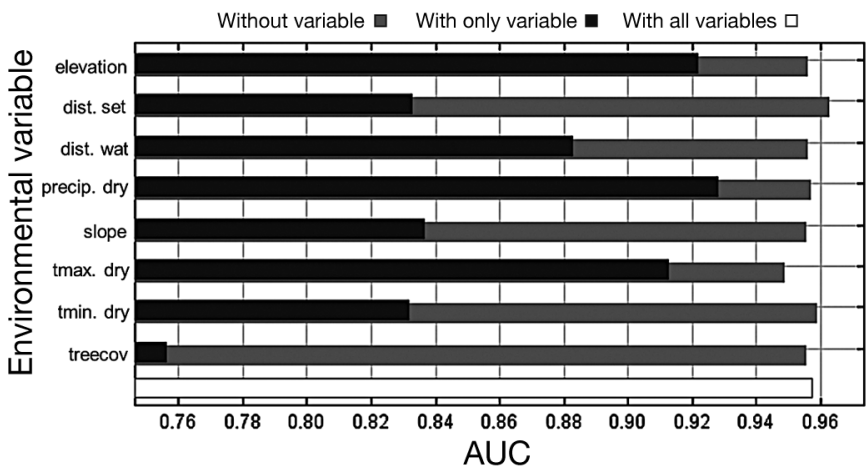

Fig. 3. Jackknife of AUC (area under the receiver operating curve) for Grevy's zebra, showing average AUC gains for each variable calculated from 25 subset models carried out for dry season habitat suitability analysis. Dist. set: distance from settlement; dist. wat: distance from water; precip. dry: precipitation of the dry season; tmax. dry: maximum temperature of the dry season; tmin. dry: minimum temperature of the dry season; treecov: tree cover. Without variable: AUC value for the model excluding that particular variable; with only variable: AUC value for the model with only this variable, i.e. excluding all others

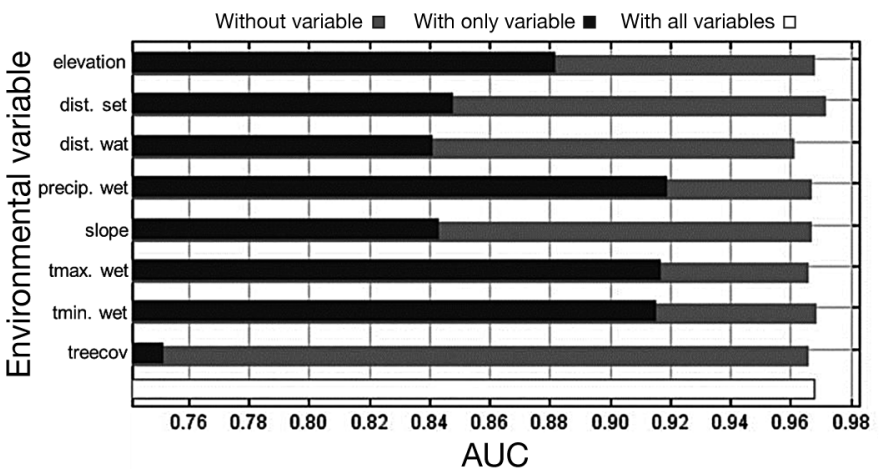

Fig. 4. Jackknife of AUC for Grevy's zebra, showing average AUC gains for each variable calculated from 25 subset models carried out for wet season habitat suitability analysis. Precip. wet: precipitation of the wet season; tmax. wet: maximum temperature of the wet season; tmin. wet: minimum temperature of the wet season. For other definitions see Fig. 3

and livestock, which, in turn, define the distribution of Grevy's zebra.

The distribution of most wild animals is often more dispersed during the wet season because of increased availability of resources across the landscape (Jachmann 1988, Bergstrom \& Skarpe 1999, Hema et al. 2010). Our model results suggested that opposite distribution patterns for the Grevy's zebra occurred in the Alledeghi Wildlife Reserve; animals were confined to a smaller geographic area during the wet season and had a wider dispersal during the dry season. During the wet season, large numbers of livestock were brought to the reserve and several temporary settlements were established (Kebede et al. 2006, 2005, 2002, Kebede 2008, Kebede \& Moehlman 2008). As a result, competition 
for rangeland between livestock and wildlife increased during the wet season, which ultimately reduced the amount of available habitat for the Grevy's zebra. During the wet season, available resources are more plentiful, allowing the Grevy's zebra to persist in high densities confined to a smaller area. During the dry season, when the number of people and livestock are reduced, the Grevy's zebra are widely dispersed and generally found in lower densities. This allows the Grevy's zebra to adjust their range to the scarcity of available resources.

The full range of the Grevy's zebra during the wet and dry seasons in the Alledeghi Wildlife Reserve was well defined by the Maxent models, and the results of the present study will guide additional management and conservation priorities. We also hope that our results will allow wildlife managers to make meaningful adjustments to the boundaries of the Alledeghi Wildlife Reserve, which was one of the major goals of our study. Further research and data collection, especially concerning the impacts of people and livestock on Grevy's zebra breeding habits, natality and survivorship, could potentially improve modeling results. However, there are several caveats that must be considered prior to making any management decisions based on our results. The strongest predictor in our models was the distance to settlement/farmland. Anthropogenic variables used in models may have greater variability than biological or topographical features. Many anthropogenic variables are directly and indirectly determined by influences that cannot be predicted, quantified, or tested (e.g. food security, economics, or politics). In this case, tribal conflicts between the Afar and Issa pastoral communities could result in territorial shifts and a redistribution of livestock and settlements. Similarly, Ethiopia is well known for extreme fluctuations in climate-especially in precipitation. Reoccurring droughts and, in rare cases, increased rainfall can also influence the distribution of both Grevy's zebra and pastoralists. The variability within each of the predictors may potentially cause wildlife populations to relocate, and modifications to the reserve's boundaries meant to protect Grevy's zebra habitat may be ineffective under future conditions.

These issues are difficult to predict and test in our models, and are perhaps better addressed through preventive strategies, adaptive management and community-based conservation measures that are sensitive to the needs of both wildlife and people utilizing the Alledeghi Wildlife Reserve.
Acknowledgements. We extend our deep thanks to EcoHealth Alliance in New York, the Model Foundation, the Saint Louis Zoo Conservation Program and the SeaWorld Busch Gardens Conservation Fund for their support and funding. We thank the Ethiopian Wildlife Conservation Authority for support and provision of permits. We are grateful to the Agriculture and Natural Resource Administration and Environmental Protection Bureau of Afar Region and local elders of the Alledeghi village, specifically to Ali Debay, Gebaba Enhaba, Ahmed Hegen and Shek Abdu. Facilities and technical expertise on modeling were provided by the Natural Resource Ecology Laboratory at Colorado State University. Lastly, we acknowledge the federal and Afar region wildlife experts Ahmed Humad, Kibebework Getachew, Kifle Argaw, Yeneneh Teka and Almaz Tadesse, who participated in fieldwork and professionally supported the previous data collection. Special thanks to Hailemariam Miruts, Lulseged Tota and Abdi Waees for their careful driving throughout the field work.

\section{LITERATURE CITED}

Baldwin RA (2009) Use of maximum entropy modeling in wildlife research. Entropy 11:854-866

Barnard P, Thuiller W (2008) Global change and biodiversity: future challenges. Biol Lett 4:553-555

Bauer IE, McMorrow J, Yalden DW (1994) The historic ranges of three equid species in North-East Africa: a quantitative comparison of environmental tolerances. J Biogeogr 21:169-182

Bergstrom R, Skarpe C (1999) The abundance of large wild herbivores in a semi-arid savanna in relation to seasons, pans and livestock. Afr J Ecol 37:12-26

Borgerhoff Mulder MB, Fazzio I, Irons W, McElreath RL and others (2010) Pastoralism and wealth inequality revisiting an old question. Curr Anthropol 51:35-48

Braunisch V, Patthey P, Arlettaz R (2011) Spatially explicit modeling of conflict zones between wildlife and snow sports: prioritizing areas for winter refuges. Ecol Appl 21: 955-967

Cowley MJR, Wilson RJ, Leon-Cortes JL, Gutirrez JL, Bulman CR, Thomas CD (2000) Habitat-based statistical models for predicting the spatial distribution of butterflies and day-flying moths in a fragmented landscape. J Appl Ecol 37:60-72

Dirschl HJ, Wetmore SP (1978) Grevy's zebra abundance and distribution in Kenya, 1977. Aerial Survey Technical Report Series No. 4, KREMU, Nairobi

Elith J, Graham CH, Anderson RP, Dudik M and others (2006) Novel methods improve prediction of species' distributions from occurrence data. Ecography 29:129-151

Evangelista P, Norman J, Berhanu L, Kumar S, Alley N (2008a) Predicting habitat suitability for the endemic mountain nyala (Tragelaphus buxtoni) in Ethiopia. Wildl Res 35:409-416

> Evangelista P, Kumar S, Stohlgren TJ, Jarnevich CS, Crall AW, Norman JB III, Barnett D (2008b) Modeling invasion for a habitat generalist and a specialist plant species. Divers Distrib 14:808-817

Ficetola GF, Thuiller W, Miaud C (2007) Prediction and validation of the potential global distribution of a problematic alien invasive species the American bullfrog. Divers Distrib 13:476-485

Gemechu D (1977) Aspects of climate and water budget in Ethiopia. Addis Ababa University Press, Addis Ababa 
Gibson LA, Wilson BA, Cahill DM, Hill J (2004) Spatial prediction of rufous bristlebird habitat in a coastal heathland: a GIS-based approach. J Appl Ecol 41:213-223

Hema EM, Barnes RFW, Guendal W (2010) The seasonal distribution of savannah elephants (Loxodonta africana africana) in Nazinga Game Ranch, southern Burkina Faso. Pachyderm 48:33-40

> Hernandez PA, Graham CH, Master LL, Albert DL (2006) The effect of sample size and species characteristics on performance of different species distribution modeling methods. Ecography 29:773-785

Hijmans RJ, Cameron SE, Parra JL, Jones PG, Jarvis A (2005) Very high resolution interpolated climate surfaces for global land areas. Int J Climatol 25:1965-1978

Hillman JC (1993) Compendium of wildlife conservation information. Information on wildlife conservation areas. NYZS and EWCO, Addis Ababa

Hutchinson GE (1957) Concluding remarks. Cold Spring Harb Symp Quant Biol 22:415-427

IUCN (International Union for Conservation of Nature) (2010) IUCN Red List of Threatened Species, Version 2010.4. Available at: www.iucnredlist.org

Jachmann H (1988) Numbers, distribution and movements of the Nazinga elephant. Pachyderm 10:16-21

Kebede F (1999) Ecology and conservation of the African wild ass (Equus africanus) in the Danakil, Ethiopia. MSc thesis, University of Kent, London

Kebede F (2008) Major wildlife species and livestock population in Alledeghi Wildlife Reserve. An independent study submitted to Addis Ababa University, Addis Ababa

Kebede AT (2009) Sustaining the Alledeghi grassland of Ethiopia: influences of pastoralism and vegetation change. PhD thesis, Utah State University, Logan, UT

Kebede F, Moehlman PD (2008) Research and conservation of the African wild ass in the Danakil Desert and the Grevy's zebra in the semi-arid areas of Ethiopia. Report to Wildlife Trust, New York, NY

Kebede F, Moehlman PD, Tadess A (2002) Research and conservation of the African wild ass in the Danakil Desert and the Grevy's zebra in the semi-arid areas of Ethiopia. Report to Wildlife Trust, New York, NY

Kebede F, Moehlman PD, Argaw K (2003) Research and conservation of the African wild ass in the Danakil Desert and the Grevy's zebra in the semi-arid areas of Ethiopia. Report to Wildlife Trust, New York, NY

Kebede F, Moehlman PD, Argaw K (2005) Research and conservation of the African wild ass in the Danakil Desert and the Grevy's zebra in the semi-arid areas of Ethiopia. Report to Wildlife Trust, New York, NY

Kebede F, Moehlman PD, Argaw K (2006) Research and conservation of the African wild ass in the Danakil Desert and the Grevy's zebra in the semi-arid areas of Ethiopia. Report to Wildlife Trust, New York, NY

KREMU (Kenya Rangeland Ecological Monitoring Unit) (1989) Livestock and wildlife data summary 1987-1988. Data summary No. 1, Department of Remote Sensing and Resource surveys, Nairobi

Kumar S, Spaulding SA, Stohlgren TJ, Hermann KA, Schmidt TS, Bahls LL (2009) Potential habitat distribution for the freshwater diatom Didymosphenia geminata in the continental US. Front Ecol Environ 7:415-420

Moehlman PD (ed) (2002) Equids: zebras, asses and horses. IUCN Status Survey and Conservation Action Plan, IUCN/SSC Equid Specialist Group, IUCN, Gland

Moehlman PD, Rubenstein DI, Kebede F (2008) Equus grevyi. In: IUCN Red List of Threatened Species, Version 2009.2. Available at: www.iucnredlist.org

Mwasi S, Mwangi E (eds) (2007) Proceedings of the national Grevy's zebra conservation strategy workshop, 11-14 April 2007. KWS Training Institute, Naivasha

Nelson APW, Williams SD (2003) Grevy's zebra survey: Kenya 2000. Kenya Wildife Service and Wildlife Conservation Research Unit, Nairobi

Norton-Griffiths M (1978) Counting animals, 2nd edn. African Wildlife Leadership Foundation, Nairobi

Pearson RG, Raxworthy CJ, Nakamura M, Peterson AT (2007) Predicting species distributions from small numbers of occurrence records: a test case using cryptic geckos in Madagascar. J Biogeogr 34:102-117

Peterson AT, Pares M, Eaton M (2007) Transferability and model evaluation in ecological niche modeling: a comparison of GARP and Maxent. Ecography 30:550-560

Phillips SJ, Dudik M, Schapire RE (2004) A maximum entropy approach to species distribution modeling. In: Proceedings of the 21st international conference on machine learning. ACM Press, New York, NY, p 655-662

> Phillips SJ, Anderson RP, Schapire RE (2006) Maximum entropy modeling of species geographic distributions. Ecol Modell 190:231-259

Rodder D, Schmidtlein S, Veith M, Lotters S (2009) Alien invasive slider turtle in unpredicted habitat: A matter of niche shift or of predictors studied? Available at: www.plosone.org

Rowen M, Ginsberg J (1992) Grevy's zebra (Equus grevyi Oustalet). In: Duncan P (eds) Zebras, asses and horses. An action plan for the conservation of wild equids. IUCN/SSC Equid Specialist Group, IUCN, Gland, p 10-12

Schloeder CA, Jacobs MJ (1993) The Awash National Park management plan (1993-1997). NYZS and EWCO, Addis Ababa

Stephenson JG (1978) The Somali wild ass (Equus africanus somalicus). Ethiopian Wildlife and Natural History Society Newsletter 119, Addis Ababa

Stockwell DRB, Peterson AT (2002) Effects of sample size on accuracy of species distribution models. Ecol Modell 148: $1-13$

Thomaes A, Kervyn T, Maes D (2008) Applying species distribution modeling for the conservation of the threatened saproxylic stag beetle (Lucanus cervus). Biol Conserv 141:1400-1410

Thorn JS, Nijman V, Smith D, Nekaris KAI (2009) Ecological niche modeling as a technique for assessing threats and setting conservation priorities for Asian slow lorises (primates: Nycticebus). Divers Dist 15:289-298

Thouless CR (1995) Aerial surveys for wildlife in eastern Ethiopia. Ecosystem Consultant, London

Williams SD (1998) Grevy's zebra: ecology in a heterogeneous environment. PhD thesis, Institute of Zoology and University College, London

Williams SD (2002) Status and action plan for Grevy's zebra (Equus grevyi). In: Moehlman PD (ed) Equids: zebras, asses and horses. Status survey and conservation action plan. IUCN/SSC Equid Specialist Group, IUCN, Gland, p 11-27

Williams SD, Nelson APW, Kebede F (2003) Grevy's zebra survey: Ethiopia 2003. Interim report, Wildlife Conservation Research Unit, University of Oxford, Oxford

York P, Evangelista P, Kumar S, Graham J, Flather C, Stohlgren T (2011) A habitat overlap analysis derived from Maxent for Tamarisk and the south-western willow flycatcher. Front Earth Sci 5:120-129 